\title{
DE INDICIBUS LIBRORUM E A ARTE DA INDICIALIZAÇÃO EM CONRAD GESNER (PARTE I ): CONTEXTO E PRINCÍPIOS
}

\author{
DE INDICIBUS LIBRORUM Y EL ARTE DE \\ INDICIALIZACIÓN EN CONRAD GESNER (PARTE I): \\ CONTEXTO Y PRINCIPIOS
}

\author{
Andre Vieira de Freitas Araujo ${ }^{a}$
}

\begin{abstract}
RESUMO
Introdução: Trata-se da primeira parte do estudo sobre De indicibus librorum - seção integrante das Pandectae (1548) de Conrad Gesner (1516-1565) - que versa sobre constituição, função e uso de índices. Objetivo: Identificar o contexto e princípios que norteiam De indicibus librorum. Metodologia: Sob abordagem histórico-bibliográfica, o estudo tem como percurso: 1) breve contextualização histórico-informacional e documental de De indicibus librorum; 2) mapeamento, leitura e tradução integral do texto latino (para Parte I do estudo, especificamente a tradução do fólio $19 \mathrm{v}$ (d) ao fólio $21 \mathrm{r}$ (d3)); 3) discussão e combinação da fonte latina com a revisão de literatura acerca do tema, sobretudo a partir de Wellisch (1981), Cochetti (1984a,1984b) e Serrai (1990). Resultados: Com base no recorte estabelecido e no intervalo de fólios analisados, o texto gesneriano apresenta as motivações, procedimentos e técnicas para composição de índices de livros por meio de "tiras" de papel e, como afirmado por Gesner, em "pouco tempo" e na "melhor ordem". Gesner rememora índices de filósofos, teólogos, gramáticos, filólogos e escritores, além de mencionar índices de tipógrafos e livreiros. Também evidencia os índices como instrumento de planejamento e controle patrimonial e bibliográfico. Para o polímata suíço, os índices possuem grande utilidade aos
\end{abstract}

\footnotetext{
${ }^{1}$ Estudo organizado em duas partes. A Parte I tem foco no contexto e princípios de De indicibus librorum; já a Parte II (em desenvolvimento) tem foco na ilustração e aplicação de índices, também a partir de De indicibus librorum e das Pandectae $(1548,1549)$ em geral. A segunda parte, intitulada De indicibus librorum e a arte da indicialização em Conrad Gesner (parte II): ilustração e aplicação, será apresentada no V Seminário Internacional A Arte da Bibliografia $A$ Bibliografia entre o local e o global: perspectivas históricas e aplicadas (UFPE, 06 e 07 de dezembro de 2018) e será publicada em 2019.

2 Este artigo é uma versão revista, ampliada e adaptada da seção "4.5 Índices e indexação" da tese de Araujo (2018), cuja pesquisa foi realizada com o apoio da Coordenação de Aperfeiçoamento de Pessoal de Nível Superior (CAPES).

a Professor Adjunto da Universidade Federal do Rio de Janeiro (UFRJ). Doutor em Ciência da Informação (PPGCI-ECA-USP) / Período Sanduíche na Alma Mater Studiorum - Università di Bologna (UNIBO). Um dos idealizadores e organizadores do Seminário Internacional A Arte da Bibliografia. E-mail: armarius.araujo@gmail.com
} 
estudiosos, pois ajudam a recordar as coisas lidas ou apresentar coisas novas, além de poupar o tempo do leitor. Conclusões: Conrad Gesner, ao apresentar uma paisagem técnica e cultural sobre a constituição, função e uso dos índices, tece críticas fundamentais em relação à indicialização, a exemplo da construção de índices sem a leitura prévia do texto, o que hoje representaria uma perspectiva oposta daquela postulada pela leitura documentária para fins de indexação. Ao mesmo tempo, Gesner destaca a importância dos índices semânticos, questão também relevante ao campo da indexação contemporânea. Neste sentido, Gesner efetivamente foi um "indexador" ao seu tempo. A sua posição, seja enquanto editor de obras e/ou como leitor, ou seja, tanto daquele que constrói quanto daquele que utiliza os índices, Ihe permitiu formular uma visão multidimensional acerca do processo de indicialização e, subliminarmente, dos processos de mediação da informação e organização do conhecimento no Séc. XVI.

Descritores: De indicibus librorum [f. 19v (d) - 21r (d3)]. Indicialização. Índice - História e Teoria. Indexação - História e Teoria. Pandectae (1548, 1549). Organização do Conhecimento - Séc. XVI.

"Vou avisar, vou avisar aos cachorros da rua que a minha ferida crua é melhor não lamber. Vou avisar, vou avisar aos cachorros da rua que pro povo pobre, a vingança pode ser mel e prazer" (Jaloo \& Mc Tha, Céu Azul).

\section{INTRODUÇÃO}

A Bibliografia é uma das disciplinas que alicerçam e alimentam teórica e metodologicamente os sistemas e procedimentos para registro, descrição, classificação, indexação e mediação documentária.

Para o bibliógrafo italiano Alfredo Serrai (2010), a Bibliografia articula-se em duas regiões teóricas e aplicadas, entretanto unidas: Bibliografia indicial e Bibliografia científica-repertorialística.

A Bibliografia indicial - categoria de maior interesse neste estudo - opera em dois níveis: o primeiro apresenta as características que permitem identificar uma obra escrita em cada uma de suas configurações textuais e o segundo 
expõe "[...] o conteúdo semântico de uma obra por meio de loci ${ }^{3}$ ou índices. Os loci são expressos com palavras não necessariamente presentes no texto, os índices com as palavras assumidas pelo texto" (SERRAI, 2010, p. 17).

No contexto da obra bibliográfica de Conrad Gesner (1516-1565), os loci expressam os conteúdos semânticos dos documentos, além de servirem como método de leitura e de armazenamento de informações ${ }^{4}$.

Em uma concepção contemporânea do campo bibliográfico, documental e informacional, os loci hospedam os assuntos dos documentos, extraídos e/ou formulados a partir de seus argumentos e conceitos (ARAUJO, 2018).

Além das habilidades específicas relativas aos índices, a Bibliografia ocupa-se das estruturas gerais - das quais os índices são os elementos - que contêm matérias cognitivas e literárias, textuais e editoriais (SERRAI, 2010).

O processo de concepção e construção de índices - aqui denominado de indicialização - herda importantes contribuições de Conrad Gesner. Exemplo mais evidente destas contribuições está em seu texto De indicibus librorum ${ }^{5}$ seção integrante das Pandectae (1548) - que versa sobre a constituição, função e uso de índices.

O estudo da indicialização na perspectiva gesneriana foi realizado por Wellisch (1981), Cochetti (1984a, 1984b) e Serrai (1990).

Wellisch (1981), em How to make an index - 16th century style: Conrad Gessner on index and catalogs, apresenta extratos da tradução de De indicibus librorum e analisa brevemente os índices das Pandectae (1548, 1549). Embora

3 Loci: "[...] conceitos, ou categorias, que expressam os temas e núcleos considerados significativos e representativos - como parte de uma das áreas de interesse e estudo de uma cultura particular - de uma obra, e que são, portanto, capazes de exprimir a informação e o conteúdo intelectual daquela obra. Em termos catalográficos os Loci, ou os índices semânticos de uma obra, são também conhecidos como assuntos ou objetos". (SERRAl, 2007, p. 13).

4 Gesner, apesar de ampliar os usos originais dos loci (aqueles intimamente vinculados à Retórica, Dialética e Memória), demonstra em sua obra bibliográfica que os loci, em realidade, carregam paralelamente componentes retóricos, mnemônicos e indiciários. Além disso, Gesner associa os loci às categorias de classificação que formula. Para estudo atualizado dos loci, no contexto gesneriano, cf. Serrai (2016).

5 "Acerca dos indices dos livros".

Inf. Inf., Londrina, v. 23, n. 2, p. 14 - 37, maio/ago. 2018.

http://www.uel.br/revistas/informacao/ 
um texto pioneiro, o mesmo não é completo e apresenta problemas do ponto de vista da tradução, o que impõem desafios à interpretação.

Cochetti (1984a, 1984b), no artigo Teoria e instruzione degli indici secondo Conrad Gessner, apresenta a tradução e comentários de De indicibus librorum do latim para o italiano, o que representa a primeira tradução integral em uma língua moderna.

Já Serrai (1990), na sua obra Conrad Gesner, realiza longa e acurada análise da obra bibliográfica gesneriana, dedicando-se também às observações de Gesner sobre os índices. Os comentários de Serrai são acompanhados pelas notas com o texto latino original.

Em complementariedade aos trabalhos supracitados e de modo a apresentar a temática e o texto traduzido ao público ibero-americano, o presente estudo tem como objetivo identificar, analisar e ilustrar as concepções de Conrad Gesner acerca da indicialização de livros.

Sob abordagem histórico-bibliográfica, o estudo tem como percurso: 1) contextualização histórico-informacional e documental de De indicibus librorum; 2) mapeamento, leitura e tradução ${ }^{7}$ integral do texto latino (para Parte I do estudo, especificamente a tradução do fólio ${ }^{8} 19 v^{9}$ (d) ${ }^{10}$ ao fólio $21 r^{11}$ (d3) ${ }^{12}$ ); 3) combinação e discussão da fonte latina com a revisão de literatura acerca do

\footnotetext{
${ }^{6}$ Algumas retificações e comentários sobre o texto de Wellisch foram publicados por Alfredo Serrai em carta destinada ao diretor da Revista International Classification, em 1981.

7 Embora Cochetti (1984a, 1984b) tenha realizado uma tradução pioneira de De indicibus librorum do latim para o italiano, para este estudo utilizamos a nossa própria tradução. Em relação a este ponto, agradecemos imensamente a Erika Werner (Humboldt-Universität zu Berlin) pela tradução do latim para o português e pelo diálogo terminológico-bibliográfico. Neste artigo, nossa tradução é mesclada com nossos comentários e discussões.

8 Fólio: "[...] folha de papel ou pergaminho numerada apenas no reto. [...] nome atribuído aos grandes livros impressos: livro in-fólio; as duas páginas de uma folha. Livro impresso em formato in-fólio". (FARIA; PERICÃO, 2008, p. 342). Adotaremos "f." para indicação dos fólios na citação direta da tradução.

${ }^{9} \mathrm{v}=$ verso.

$10 \mathrm{~d}$ = caderno. "Caderno: conjunto de folhas de pergaminho ou papel dobradas ao meio, encartadas umas nas outras e constituindo os elementos de um manuscrito ou de um livro. Cada uma das folhas de impressão, dobrada segundo o número de páginas que contém e identificada por uma assinatura, que permite a sua reunião obtendo-se, deste modo, um número par de folhas" (FARIA; PERICÃO, 2008, p. 120).

${ }^{11} \mathrm{r}=$ reto.

$12 \mathrm{Na}$ Parte II do estudo, apresentaremos a tradução do intervalo do fólio $21 \mathrm{r}$ (d3) ao fólio $22 \mathrm{v}$ (d4).
}

Inf. Inf., Londrina, v. 23, n. 2, p. 14 - 37, maio/ago. 2018.

http://www.uel.br/revistas/informacao/ 
tema sobretudo a partir de Wellisch (1981), Cochetti (1984a,1984b) e Serrai (1990).

\section{BREVE CONTEXTUALIZAÇÃO HISTÓRICO-INFORMACIONAL E DOCUMENTAL}

O Séc. XVI é demarcado pela chamada "explosão informacional" resultante da crescente produção e difusão do documento impresso e da tecnologia do tipo móvel, cujo advento ocorreu no século anterior.

A propagação da Imprensa Tipográfica de Gutenberg configura uma progressiva aceleração do número de livros disponíveis que, nos dois séculos anteriores, já tinha se estendido. Ainda que, desde a "invenção" gutenberguiana, os efeitos na organização bibliográfica tenham levado quase um século para se tornar evidentes, não há dúvida de que o interesse pelo documento impresso despertou mudanças culturais profundas na Europa, na fase em que a reprodução dos livros passou progressivamente dos scriptoria para as oficinas dos impressores (ARAUJO; CRIPPA, 2016).

Do ponto de vista estritamente quantitativo, enquanto que na Europa Medieval vive-se os desafios da pouquidade de livros ${ }^{13}$, na Europa Moderna vivese o seu excesso como um problema.

A alta produção documentária e textual na Europa Moderna, em contraposição à escassez do Medievo, é ilustrada por metáforas e analogias como labirinto, floresta, oceano, e uma série de outros termos que evocam a ideia de um lugar hostil e perigoso, reveladoras do problema do acesso e dos critérios a serem adotados para a seleção e a recuperação dos documentos (BURKE, 2002).

Os estudiosos, ou mais genericamente os que buscassem o conhecimento, também enfrentavam problemas. Observemos deste ponto de vista a assim-chamada "explosão" da informação - uma metáfora desconfortável que faz lembrar a pólvora subsequente à invenção da imprensa. A informação se alastrou "em quantidades nunca vistas e numa velocidade inaudita".

${ }^{13}$ Todavia, o livro no Medievo é objeto presente, porém distante da população. 
Alguns estudiosos logo notaram as desvantagens do novo sistema. [...] Mais sério ainda era o problema da preservação da informação e, ligado a isso, o da seleção e crítica de livros e autores. Em outras palavras, a nova invenção [a imprensa] produziu uma necessidade de novos métodos de gerenciamento da informação. (BURKE, 2002, p. 175).

A mesma paisagem apresentada por Burke é discutida pela historiadora da cultura Ann Blair, mas a partir do exame daquilo que anacronicamente pode ser chamado de "gestão da informação" no contexto pré-moderno, com enfoque especial para o impacto da imprensa na Europa do Séc. XVI e XVII.

Blair (2010) examina os livros de referência no início da Europa Moderna e como eles foram concebidos, produzidos e utilizados por estudiosos em um contexto em que a recuperação, a seleção e a organização da informação tornam-se elementos de propriedade pública.

Sob a ótica histórico-informacional, a necessidade de circulação, leitura e apropriação do impresso impõe demandas como o mapeamento documentário e a busca por estratégias para localização de informações no interior dos textos. Estamos aqui diante dos desafios relativos à "gestão e recuperação da informação"14 no início da Europa Moderna.

Portanto, no Séc. XVI, o tema da multidão de livros passa a ser muito evidente e se espelha diretamente na produção documentos diversos: livros sobre livros, livros que discutem livros, livros que exaltam livros, livros que anunciam amor aos livros e livros que tentam discutir como devem ser organizados e apresentados os livros, como revisões, catálogos e enciclopédias. Tais tipologias documentárias que incluem catálogos e enciclopédias não são fenômenos inerentes à Europa Moderna, pois já se encontram em épocas anteriores. Todavia, essa é uma época em que se busca uma sistemática bibliográfica, e essa é o grande diferencial que podemos observar (ARAUJO, CRIPPA, 2016).

Livros antigos de referência foram designados para tornar acessível palavras, coisas e pessoas. Neste sentido, os índices teriam justamente esta

\footnotetext{
${ }^{14}$ Mais uma vez, o uso deste termo é anacrônico no contexto do Séc. XVI.
} 
função de potencialização do acesso informacional.

É neste cenário histórico-informacional da Europa Moderna que floresce Conrad Gesner e sua monumental obra bibliográfica Bibliotheca Universalis.

Bibliotheca Universalis é constituída por uma parte alfabético-nominal designada Bibliotheca Universalis (1545) e pelas Pandectae (1548b, 1549), que são ordenadas sistematicamente, a partir do conteúdo semântico das obras ${ }^{15}$. Portanto Biblioteca Universalis é uma obra única, mas publicada por partes (ARAUJO, 2018).

Bibliotheca Universalis (1545) oferece uma descrição crítica das obras elencadas em ordem alfabética dos nomes dos autores, enquanto as Pandectae (1548b, 1549) apresentam referências sucintas das fontes apontadas em Bibliotheca Universalis (1545), mas desta vez divididas em tópicos de acordo com um esquema de classificação em 21 classes ou partições ${ }^{16}$.

A Partição I De Grammatica, que dedica-se ao tema dos loci e dos índices, contêm XXI títulos. No Título XIII, De variis, figura a parte 2 denominada De indicibus librorum que, como já mencionado, integra acurada discussão acerca dos índices.

Para Cochetti (1984a, p. 25):

[...] é surpreendente encontrar no meio do Séc. XVI, na única bibliografia universal da idade moderna, Bibliotheca Universalis de Conrad Gessner, uma discussão de índices que para completude e grau de elaboração não só não tem precedentes, mas permaneceu por séculos sem seguidores. [...] Com seu repertório, ele pretendia fornecer um instrumento para aliviar o sentimento de perda gerado pela expansão de uma produção editorial cada vez menos dominante pela erudição individual, uma ferramenta que foi sutilmente articulada para responder às diferentes necessidades da pesquisa documental.

Gesner inclui em seu projeto bibliográfico a tipologia de obras que devem dar suporte para leitura e compreensão de outros livros. O programa bibliográfico

\footnotetext{
15 Inúmeros aspectos teóricos e metodológicos do campo da Bibliografia são anunciados e discutidos a partir de Bibliotheca Universalis (1545) e das Pandectae (1548b, 1549), de onde emerge o método bibliográfico de Conrad Gesner. No que toca a este método, cf. Araujo (2018). Naturalmente, para este artigo, nos atemos especificamente às questões de indicialização.

16 Para apresentação geral e sucinta do sistema de classificação de Conrad Gesner nas Pandectae (1548b, 1549), ver Araujo, Crippa e Sabba (2016).
}

Inf. Inf., Londrina, v. 23, n. 2, p. 14 - 37, maio/ago. 2018. http://www.uel.br/revistas/informacao/ 
gesneriano - detalhadamente concebido e articulado em Bibliotheca Universalis - nasce com o objetivo de repertoriar e sistematizar semanticamente expressivo patrimônio bibliográfico em latim, grego e hebraico, além de contribuir para uma profunda reflexão sobre o domínio bibliográfico, incluindo a concepção e construção de índices - a indicialização.

\section{DE INDICIBUS LIBRORUM: PRINCÍPIOS INDICIAIS}

Em De indicibus librorum (Fig. 1), Gesner manifesta ampla consciência da função dos índices.

Por meio de uma exposição detalhada, o texto explicita a unidade substancial dos processos de indexação, refletida em produtos e resultados, tais como: índices de livros (por nomes e argumentos), compilações que servem a funções de recuperação (margaritae, dicionários, concordâncias, inventários, resumos) e coleções de citações de uso pessoal (COCHETTI, 1984a). 
Figura 1: Início da seção De indicibus librorum, pars 2 (De Grammatica, Pandectae, 1548)

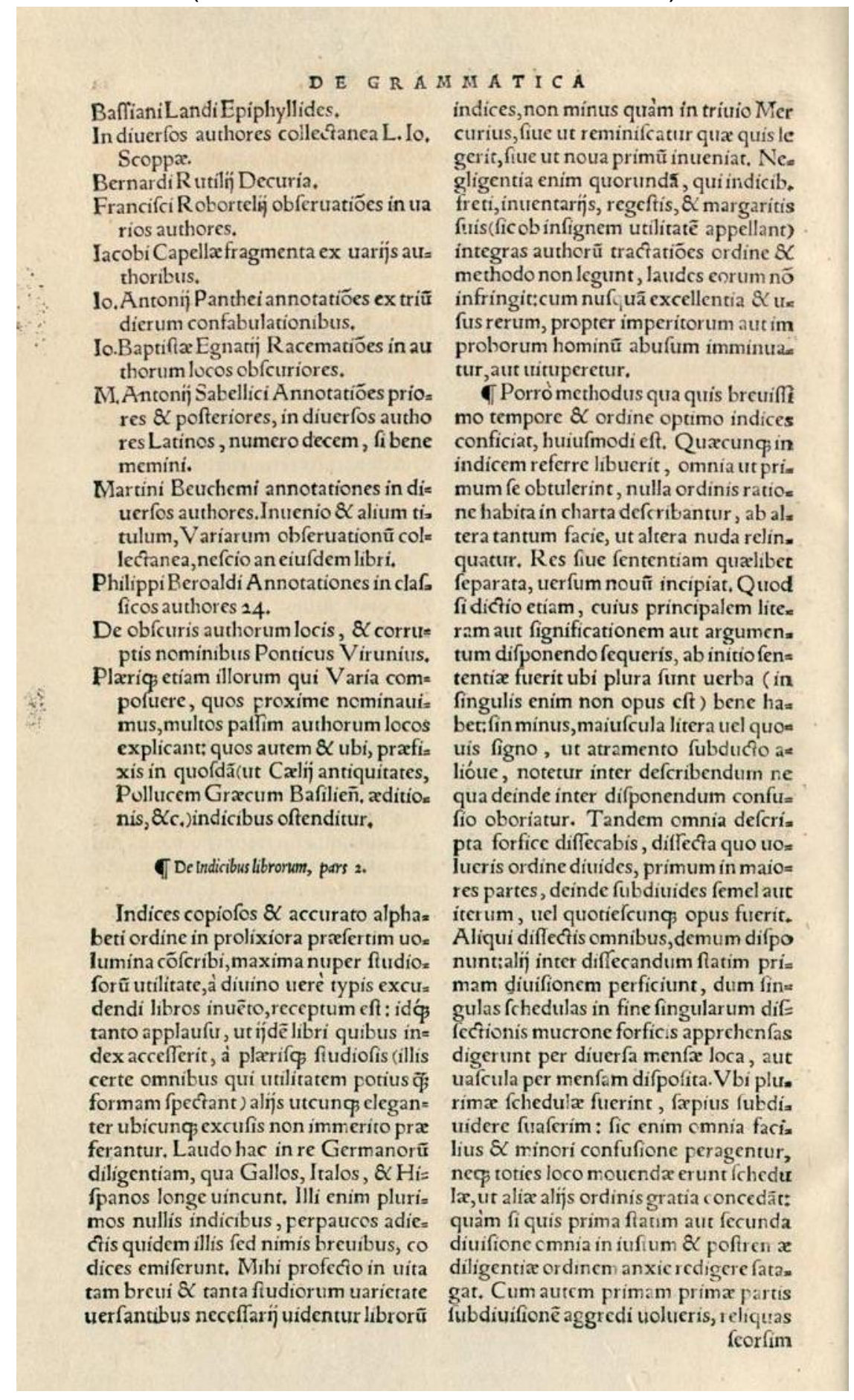

Fonte: Gesner (1548a, f. [19v (d)]).

Disponível em: <https://www.e-rara.ch/zuz/content/pageview/625009>.

Inf. Inf., Londrina, v. 23, n. 2, p. 14 - 37, maio/ago. 2018. http://www.uel.br/revistas/informacao/ 
Com as seguintes palavras Conrad Gesner abre De indicibus librorum:

É de supor que índices grandiosos e em uma acurada ordem alfabética sejam arrolados nos volumes, especialmente naqueles maiores, já que recentemente eles têm se mostrado de máxima utilidade para os estudiosos, desde a maravilhosa descoberta de [como] produzir livros com o uso de tipos ${ }^{17}$. $E$ isso [é feito] sob muito aplauso, já que esses mesmos livros, nos quais um índice teria sido adicionado, seriam merecidamente preferidos por muitos estudiosos (de certo por todos aqueles que prefeririam a utilidade [deles] a sua beleza) ao invés de outros [livros] produzidos de modo elegante em qualquer outra época ou lugar. (GESNER, 1548b, f. [19v (d)]).

Para Gesner, livros com índices seriam priorizados pelos estudiosos, pois estes preferem a utilidade dos livros do que a sua beleza.

A diligência dos alemães é elogiada por Gesner, já que eles superariam os franceses, italianos e espanhóis em relação à publicação de livros com índices.

Para Gesner, o índice teria uma função de recordar coisas lidas ou apresentar coisas novas, além de poupar o tempo do leitor, considerando a brevidade da vida.

Sendo a vida tão breve e com uma tamanha variedade de estudos com os quais se ocupar, os índices dos livros me parecem ser não menos necessários do que Mercúrio em um trívio ${ }^{18}$, já que [o índice] ou recorda as coisas que alguém teria lido ou apresenta primeiramente coisas novas. A negligência de alguns, que não leem, com ordem e método, as discussões completas dos autores, mas se baseiam [apenas] em seus índices, inventários, registros e pérolas (assim eles as nomeiam por conta de sua insigne utilidade), não diminui o mérito dos [índices], já que a excelência e a utilidade dessas coisas nunca seriam diminuídas ou recriminadas por conta do abuso de [alguns] homens imperitos e ímprobos. (GESNER, 1548b, f. [19v (d)]).

Partindo da ênfase sobre a utilidade dos índices para os estudiosos, Gesner explora a tipologia de índices e a técnica para sua configuração. Apresenta, assim, uma espécie de método sobre como produzir índices em

17 Desde a invenção da Imprensa.

18 Uma herma em uma encruzilhada.

Inf. Inf., Londrina, v. 23, n. 2, p. 14 - 37, maio/ago. 2018. http://www.uel.br/revistas/informacao/ 


\section{"pouquíssimo tempo" e na "melhor ordem":}

A seguir, [apresento] como uma espécie de método sobre como alguém poderia produzir índices em pouquíssimo tempo e na melhor ordem. Quaisquer coisas que seriam desejáveis representar em um índice, todas elas seriam transcritas em um papel sem nenhuma espécie de ordem, assim como elas teriam primeiro se mostrado, em apenas uma face [da folha], de modo que a outra permaneça vazia. Após tê-las dividido em conceitos ou em sentenças, como for preferível, inicia-se uma nova linha. Mas se uma palavra, porém, a qual desejas ordenar de acordo com sua primeira letra, significado ou temática, estiver no início da frase, na qual há muitas palavras (pois com palavras sozinhas não há necessidade disso), isso é uma vantagem. Se, ao contrário, com uma letra maiúscula ou com qualquer outro sinal, como sublinhado com tinta preta ou algum outro [sinal], isso deve ser observado ao se transcrever [o texto] para que não ocorra a seguir alguma confusão entre o que deve ser ordenado. Por fim, separarás com uma tesoura todas as coisas transcritas, dividirás as coisas separadas na ordem que desejares, primeiramente em partes maiores, depois as subdividirás mais uma ou duas vezes ou quantas vezes forem necessárias. Alguns somente as ordena após ter separado todas elas, outros já realizam uma primeira divisão durante o processo de separação, enquanto dividem cada uma das tiras de papel em pedaços separados, tendo cortado cada uma delas com as pontas afiadas da tesoura, por diversos pontos da mesa ou em pequenos recipientes dispostos pela mesa. Onde houver muitas tiras de papel, eu recomendaria subdividir mais vezes. Assim, portanto, tudo será executado de forma mais fácil e com menos confusão e nem as tiras deverão ser mudadas muitas vezes de lugar, visto que elas serão retiradas uma após a outra graças a essa ordenação, do que se alguém se apressar em juntar tudo, de forma ansiosa, já na primeira ou segunda divisão dentro da ordem correta e com especial diligência. Quando desejares, porém, começar a primeira subdivisão da primeira parte, recoloca todas as outras tiras de papel em outros recipientes ou entre as páginas dos livros. E assim volta a subdividir a primeira parte na ordem que desejares, ou rearranja a [parte] então ordenada se for necessário, ou se o primeiro arranjo já estiver bastante satisfatório, o que seria preferível, cola [as tiras] com cola de farinha [e], se não misturares xilocola ${ }^{19}$ ou alguma cola artificial a ela, facilmente descolarás ou removerás as coisas coladas, pois elas se soltarão se forem molhadas com um pouco de água, se houver algum erro ou se pensares em uma nova ordenação para um uso diferente. Por causa disso, muitos preferem colá-las somente em um único lado da folha, para que eles possam separá-las novamente quando lhes for conveniente. (GESNER, 1548b, f. [19v (d)] - 20r (d2)).

${ }^{19}$ Aparentemente uma cola especial para madeira.

Inf. Inf., Londrina, v. 23, n. 2, p. 14 - 37, maio/ago. 2018.

http://www.uel.br/revistas/informacao/ 
Constituir um esquema concreto de como ocorria o método relatado por Gesner não é uma tarefa simples. Mas é possível compreender que ele sugeria a listagem de termos em um fólio (com o verso em branco), após a leitura de partes dos livros (como os prefácios).

Primeiramente não há uma ordenação dos termos, pois o leitor (indexador, em uma terminologia contemporânea) deve se preocupar com 0 aspecto semântico dos documentos.

Em seguida, os termos deveriam ser cortados em "tiras" de papel. O corte poderia ser tão veloz ao ponto da "tira" ficar presa à tesoura.

Gesner foi o primeiro a recomendar a utilização de tiras" para criar um índice alfabético: cada item a ser alfabetizado seria copiado em um único lado do papel que seria cortado em deslizamentos. Em um procedimento mais radical projetado para economizar o tempo e esforço de copiar, Gesner recomendava sempre que possível cortar a passagem diretamente do livro impresso (BLAIR, 2010).

A ideia de Gesner seria então criar os índices a partir deste conjunto de termos previamente recortados. A ordenação ficaria a critério de cada um.

Por fim, os termos (em tiras) seriam colados em um fólio. Outra possibilidade seria inserir as tiras com um fio em livros mais grossos. Assim, um caderno de índices poderia ser criado. Neste caso, este caderno teria a função dos livros de loci em formato de fólios.

Há aqueles que não colam [essas tiras], mas inserem[-nas] com fios em um livro em particular. Eles montam um livro com um papel mais grosso e mais compacto, no formato de um fólio (como eles o chamam), e, indo de cima até embaixo, eles costuram quatro fios descendo em linha reta, equidistantes, os quais são presos a parte superior, central e inferior do fólio. [...] Desse modo, cerca de cem fólios, guarnecidos com tiras e fios, poderiam ser adicionados a um único códice (de outro modo, o livro ficaria grosso demais ou permaneceria aberto). Com esse método, Georg Joachim Rheticus, o mais ilustre matemático desta época, compilou as Pandectas acerca dos julgamentos da astronomia. (GESNER, 1548, f. 20r (d2)).

Estamos falando aqui de livros com listas de sentenças ou termos ordenados, que expressam os argumentos dos livros. Estes termos teriam 
efetivamente a função de termos indexadores com o mesmo propósito que conhecemos hoje nos processos de busca e recuperação da informação.

Gesner conheceu muitos homens eruditos que utilizaram este método de organização do material compilado, seja para escrever sobre um tema, seja na preparação de uma fala pública, poupando-se de muito trabalho. Estes estudiosos

[...] arranjariam desse modo o material compilado e ainda não polido de seu discurso, seja quando eles tivessem acumulado mais material recentemente ou reservassem o [material] coletado para o utilizarem em outra ocasião, sem terem colado cada uma das tiras em seus lugares, de modo que, quando fosse necessário, eles pudessem tratar de qualquer tema e, dentre essas muitas [tiras], eles selecionariam as que no momento parecem mais contribuir para esse propósito, as prenderiam com alfinetes e ordenariam, do modo que desejarem, a organização dessas partes do discurso e transcreveriam o que eles veem ou utilizariam seu próprio arbítrio e as colocariam de volta em seus lugares. O material, porém, é coletado em parte ao se transcrever as coisas que alguém teria observado aos poucos durante a leitura, em parte após se dissecar os loci communes dos autores ou outras [passagens] de um livro, para o que é necessário utilizar dois exemplares [do livro]: em um deles a frente [do fólio] deve ser obliterada com tinta preta ou vermelha e no outro o verso [do fólio], de modo que a partir dos dois seja criado uma espécie de novo exemplar. (GESNER, 1548, f. 20r (d2)).

A compilação do material em "tiras" de papel constituiria uma espécie de "banco de dados" onde o estudioso pudesse recuperar a informação (seja as coisas, os discursos ou as pessoas) e utilizá-la de diferentes formas e em diferentes contextos específicos.

Em resumo, é possível apreender duas funções das "tiras" gesnerianas que estão intimamente interligadas:

1) sintetizar e posicionar os argumentos dos livros - apresentados como termos ou expressões - para construção de índices;

2) alimentar um "banco de dados" à disposição do estudioso para organização de seu discurso a ser revisitado, por exemplo, na escrita ou na elaboração de uma fala pública.

Gesner enfatiza a eficiência deste método:

Inf. Inf., Londrina, v. 23, n. 2, p. 14 - 37, maio/ago. 2018. http://www.uel.br/revistas/informacao/ 
Por meio desse método, será possível ser poupado certamente de muito trabalho e obter várias vantagens para os estudos. Sobre isso já se falou o suficiente, mais do que minha intenção. A utilidade dessa insigne empreitada de certo me compeliu para esta digressão, [empreitada] que ninguém, a não ser um especialista, teria facilmente estimado quão importante ela seria. Não apenas se poupa com esse método tempo e trabalho e o cansaço de se escrever (soma-se a isso que alguém poderia ser beneficiado ao mesmo tempo também por duas ou mais dentre todas essas coisas, isto é, transcrever, separar e colar), mas esse método é quase inevitável para se ordenar conceitos e palavras, para que [essa ordenação] se mostre a mais acurada possível. A própria prática é realmente mestre da perfeição e ela ensinará a utilizar corretamente os [métodos] que eu apresentei e a inventar novos [métodos] além desses. (GESNER, 1548, f. 20r (d2)).

Para Considine (2015), presumivelmente Gesner estava, ao relatar o seu método de "tiras", descrevendo as técnicas pelo qual se apoiou para preparar as Pandectae, o que se torna a primeira evidência inequívoca para a manipulação de informações por meio de "tiras" de papel.

Seguindo a seção De indicibus librorum, Gesner menciona a existência de índices grandiosos, dignos de serem recordados e que pertencem a determinados gêneros de estudo,

[...] como aquele que o excelente e muito douto filósofo de propícia memória Hieronymus Gemuseus produziu há pouco, de modo muito diligente, para todas as obras latinas de Galeno, o qual foi publicado em Basel pela oficina Frobeniana ${ }^{20}$. Os jurisconsultos também possuem muitas e importantes pérolas e os teólogos suas Concordâncias e outros índices [...]. Não há em geral nenhum livro que não conteria vários assuntos, seja porque seu argumento possibilita isso, já que há uma grande afinidade entre muitas áreas do conhecimento e estudos, seja por imperícia dos escritores. Aristóteles e outros entre os mais doutos filósofos da Antiguidade não adicionam em geral nada externo à área do conhecimento com a qual eles claramente se ocupam, mas se mantêm, em grande medida, dentro dos limites dela. Muitos [autores] posteriores e mais imperitos transitam sem medo de um gênero para outro, de onde surgem grande confusão, perda de tempo e dificuldade de aprender e se perde [com isso] todo o resultado do método. (GESNER, 1548, f. [20v (d2)]).

${ }^{20}$ Casa editoral de Johann Froben.

Inf. Inf., Londrina, v. 23, n. 2, p. 14 - 37, maio/ago. 2018.

http://www.uel.br/revistas/informacao/ 
Gesner cita índices diversos pertencentes a gramáticos, filólogos e escritores de várias áreas que se referem a livros inteiros, "[...] de modo que eles não deixam de fora nenhuma palavra, interessando-se mais pelas palavras do que pelos temas" (GESNER, 1548, f. [20v (d2)]).

Alguns exemplos apontados por Gesner:

1) índice de Nicolaus Erythraeus para Virgílio, no qual ele teria apontado, se tivesse vivido, quais excelentes autores gregos e latinos se mostrariam semelhantes a ele, graças a seu conhecimento não apenas do estilo, mas também dos temas de Virgílio.

2) O índice de Mario Nizolio para Cícero.

3) A epítome de palavras latinas de Basilius Zanchi e o apêndice do índice de Nizolio.

4) Concordâncias bíblicas, e outras obras.

Alguns são índices de assuntos ou de todas as coisas dignas de nota, nos quais são indicadas não somente as palavras, todas elas de maneira breve, mas também obras, vultos históricos e efemérides. Este tipo de índice costuma ser publicado e dedicado a muitos autores.

Segundo Gesner, existem aqueles índices que fazem menção a todas as palavras e assuntos.

Outros distinguem [essas coisas] de acordo com determinada ordem, como [no índice] que alguém escreveu para [Aulo] Gélio, onde são indicados separadamente os termos gramaticais, os termos filosóficos e outros. Alguns também distinguem [termos] gregos dos latinos, como no [índice] para Ateneu, no [índice] para Pólux, nos comentários de [Guilherme] Budé, nos quais os vocábulos latinos são apresentados em um índice e os gregos em outro. O [índice] para as Antiguidades de Caelius [Rhodiginus], o qual de certo é muito completo e útil, mistura [vocábulos] gregos e latinos. (GESNER, 1548, f. [20v (d2)]).

Gesner observa que, eventualmente, há índices que demonstram os números dos fólios, seja de forma muito simples ou de forma mais rebuscada, onde o número das seções e das linhas são adicionados. A estima de Gesner está naqueles que se referem ao número dos livros e dos capítulos: 
Eu estimo sobretudo aqueles que se referem ao número dos livros e dos capítulos, porque esses se adaptam a todas às edições em qualquer formato, como aquele que [Johannes] Camers preparou outrora para a História Natural de Plínio, após ter dividido em algumas partes todos os capítulos que eram mais longos. Embora muitos livros, porém, não sejam divididos em capítulos, seria possível executar essa divisão dos capítulos também na própria obra para a qual se produz o índice. Eu, há pouco, em parte comentei todas as obras gregas de Aristóteles, as quais aguardamos serem publicadas em breve, de forma muito emendada, pela muito ilustre oficina tipográfica de Isengrin ${ }^{21}$, com novos capítulos e argumentos, em parte conservei a antiga divisão empregada em seus livros em latim, de modo que todo Aristóteles se encontra agora dividido em capítulos. O mesmo comecei a fazer nas obras de Cl[áudio] Galeno. (GESNER, 1548, f. [20v (d2)]).

Aqueles que compõem os índices somente a partir dos títulos dos capítulos, sem os ter lido, são criticados por Gesner, uma vez que a composição do índice estaria empobrecida. Do mesmo modo, Gesner também critica e reprova aqueles que colocam, no início da obra, os argumentos de cada um dos capítulos no lugar de um índice, o que reforça a importância documentária do saber/fazer indicial para o polímata suíço.

Gesner exalta aquele que foi seu mentor, Konrad Pellikan (1478-1556):

Konrad Pellikan, meu preceptor, homem muito diligente e exímio conhecedor das literaturas clássicas, sobretudo as sacras, compôs, na Basileia, [índices] para Tertuliano, para Hilário, para a História Eclesiástica Tripartite ${ }^{22}$, para todas as obras de Jerônimo e o tríplice índice para a História Natural de Plínio. E também compôs comigo [índices] para o Velho e Novo Testamento, o qual se concentra mais nos argumentos do que nas palavras. (GESNER, 1548, f. [20v (d2)]).

Concentrar a construção de índices mais nos argumentos do que nas palavras significa, para Gesner, propor um método de indexação a partir dos conceitos e não necessariamente pelas palavras dos documentos ${ }^{23}$.

Gesner menciona uma extensa lista de índices de obras, de tipógrafos e de bibliotecas, que constituíram referencias fundamentais para Bibliotheca Universalis.

\footnotetext{
21 Oficina tipográfica de Michael Isengrin em Basileia.

22 Escrita por Cassiodoro.

23 Vemos, portanto, duas questões clássicas assimiladas e presentes no campo da indexação contemporânea: a utilização de palavras $x$ conceitos. Tal temática associa-se diretamente à construção das linguagens naturais $x$ linguagens documentárias.
} 
Os índices citados, acerca das obras, são:

Florentius Burgoinus Parisiensis, religioso franciscano, ampliou, de forma notável, o índice de todos as máximas de Santo Agostinho. Um índice muito extenso foi anexado à edição de Froben das obras de Santo Agostinho, como também em muitos outros livros daquela oficina. Agora também me vêm à mente os índices que essa mesma oficina produziu para os comentários que Antonio Musa Brassavola para os Aforismos de Hipócrates e também para a Historia stirpium ${ }^{24}$ de Jean Ruel.

Um excelente e muito extenso índice para as obras gregas de Platão se encontra na edição basilense ${ }^{25}$ do muito diligente tipógrafo de propícia memória [Johannes] Walder, o qual foi sucedido por seu filho adotivo Hieronymus ${ }^{26}$.

O índice para as obras de Platão em latim, menos extenso, é da oficina de Froben.

O índice para as obras de Aristóteles em latim editadas na Basileia são sucintos demais em relação a toda a obra supérstite, mas bastante copioso no caso dos livros De partibus animalium $^{27}$, De generatione animalium ${ }^{28}$ e Historia animalium ${ }^{29}$ e de um outro índice separado para os Problemata ${ }^{30}$.

A Tabula dilucidationum in dicta Aristoteles et Averrois ${ }^{31}$, onde palavras e sentenças são apresentadas brevemente, em ordem alfabética, segundo todas as partes da filosofia, de M[arco] Antonio Zimara.

Hieronymus Guntius elaborou um índice, também em grego, excelente e muito completo para o Léxico grego de Varino Favorino de Camerino, publicado em Basileia, o qual, após ser editado separadamente, os estudiosos podiam comprar junto com a obra.

Um índice grego muito amplo e outro latino para a obra de Pólux editada na Basileia.

Alguns excelentes índices para a obra de Dioscórides em grego a partir da edição de Colônia, com a interpretação de Marcellus Vergilius e corolário de Ermolao Barbaro.

Um índice muito rico para a obra Castigationes Plinianae de Ermolao Barbaro a partir da edição da Basileia.

Índices para Alessandro Alessandri, as Miscellanea de Poliziano para Crinito e muitos outros, que escreveram sobre vários temas.

Para as obras morais de Plutarco em latim, publicadas em Basilieia.

Para as Vidas, do mesmo autor, em latim, publicadas na oficina de Isengrin.

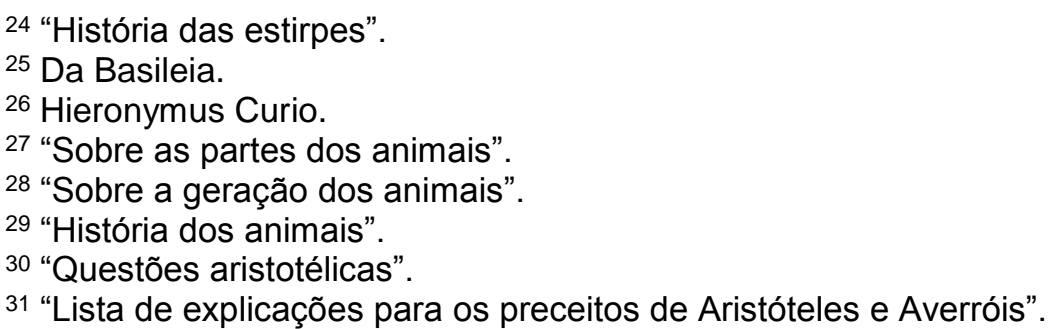

Inf. Inf., Londrina, v. 23, n. 2, p. 14 - 37, maio/ago. 2018.

http://www.uel.br/revistas/informacao/ 
Para as obras de [Andrea] Alciato, publicadas na mesma oficina tipográfica.

Índice das denominações geográficas na obra de Ptolomeu, Estrabão, Pausânias e outros, elaborado por nosso Johann Wolff, ainda não publicado.

Um extenso índice para o Magister sententiarum ${ }^{32}$, o qual também apresentará uma concordância dos vários escritores e monges que escreveram súmulas e comentários sobre essa obra. (GESNER, 1548, f. 21r (d3)).

Gesner lembra dos tipógrafos e livreiros, especialmente aqueles providos de mais livros, que fornecem listas e índices nos livros por eles impressos ou vendidos,

[...] alguns dos quais também impressos em livrinhos ${ }^{33}$, como, por exemplo:

no [catálogo] de Aldo Manúcio, [no formato] fólio, em três páginas;

no [catálogo] de nosso Froschauer, o qual eu compilei, [no formato] oitavo, em duas páginas;

no [catálogo] Cratander da Basileia, tipógrafo que já morreu;

nos [catálogos] dos parisienses Robert Estienne, [Simon de] Collines e [Christian] Wechel, três muito proeminentes tipógrafos.

São impressos também os índices de muitos outros tipógrafos basilenses, como os de Froben, Isengrin, Heinrich Petri, Herwagen, Oporinus e Robert Winter, e também o de Gymnicus de Colônia. (GESNER, 1548, f. 21r (d3)).

Gesner utilizou esses e outros manuscritos gregos, latinos e hebraicos de tipógrafos e livreiros - muitos dos quais também possuem índices impressos nos livros por eles vendidos ou publicados - para ampliar a primeira parte de Bibliotheca, ou seja, Bibliotheca Universalis (1545).

As "tiras" gesnerianas possuem duas funções coligadas: 1) a síntese e 0 posicionamento dos argumentos dos livros, por meio de termos ou expressões, para composição dos índices e 2) a alimentação de um "banco de dados" à disposição do estudioso para escrita ou elaboração de uma fala pública.

Como vimos, Gesner rememora índices de filósofos, teólogos, gramáticos, filólogos e escritores, além de mencionar índices de tipógrafos e livreiros. Por meio deste trajeto, apresenta fontes/índices históricos que comprovam as distintas naturezas, configurações e funções do trabalho indicial.

32 Escrito por Pietro Lombardo.

33 i.e. na forma de catálogos impressos.

Inf. Inf., Londrina, v. 23, n. 2, p. 14 - 37, maio/ago. 2018.

http://www.uel.br/revistas/informacao/ 
Os índices são, portanto, instrumentos de planejamento e de controle patrimonial e bibliográfico. Para o polímata suíço, os índices possuem grande utilidade aos estudiosos, pois ajudam a recordar as coisas lidas ou apresentar coisas novas, além de poupar o tempo do leitor.

Em síntese, o que Gesner mobiliza em De indicibus librorum é um conjunto de princípios basilares à teoria e à prática de indicialização. Do fólio $19 \mathrm{v}$ (d) até o fólio $21 \mathrm{r}$ (d3), Gesner evidentemente lança luz sobre o alicerce formal das distintas tipologias de índices, considerando, portanto, que a dimensão documentária dos índices associa-se diretamente à sua composição, estrutura e uso. Para Gesner, os índices podem, portanto:

a) apreender todas as palavras de um livro; b) propor apenas os assuntos de uma obra, todos ou os mais relevantes; a sinalização dos assuntos pode envolver e compreender parte das palavras, obviamente as mais significativas, contidas no texto; c) citar em uma única série os termos utilizados no texto e aqueles utilizados como descritores dos assuntos; d) distinguir, em listas ordenadas separadamente, os termos relativos a diferentes disciplinas; e) separar os vocabulários gregos dos latinos, ou reuni-los; f) acompanhar as entradas do índice com a indicação da folha ou número da página; em alguns casos, também especificando o número da linha ou conotando as diferentes partes da página mediante o uso de letras; g) dispor as referências, das entradas do índice, aos livros individuais e aos capítulos relativos da obra: para que, totalmente livres da paginação, sejam válidos para qualquer edição. (SERRAI, 1990, p. 147-148).

Deste modo, Serrai sintetiza, de forma precisa e magistral, as proposições gesnerianas acerca dos índices e evidencia os princípios indiciais que ainda sustentam a teoria e a prática de indicialização nos dias de hoje.

\section{CONSIDERAÇÕES}

Como vimos, as Pandectae (1548) gesnerianas abarcam instruções detalhadas sobre a elaboração de índices e trechos de trabalhos científicos, incluindo sua técnica de preparação. Gesner deu conselhos a compilação de bibliotecas em catálogos e listou muitos índices para trabalhos de estudiosos 
conhecidos em sua época. Para Wellisch (1981), este é provavelmente é o mais antigo trabalho que discute técnicas bibliográficas.

Conrad Gesner, ao apresentar uma paisagem técnica e cultural sobre a constituição, função e uso dos índices, tece críticas fundamentais em relação à indicialização, a exemplo da construção de índices sem a leitura prévia do texto, o que hoje representaria uma perspectiva oposta daquela postulada pela leitura documentária para fins de indexação. Ao mesmo tempo, Gesner destaca a importância dos índices semânticos, questão também relevante ao campo da indexação contemporânea.

A proposição de Gesner para indicialização atravessa autores, obras, contextos geográficos e culturais, autores de índices, técnicas de índices, tipógrafos, comerciantes, livreiros etc., o que rompe a dimensão estritamente técnica do trabalho indicial.

A indexação implica compreensão e análise da obra, pois visa enumerar significados. Como afirma Cochetti (1984a, p. 27),

[...] o indexador é também o editor de uma edição e, às vezes, responsável por organizar o texto em livros, capítulos, parágrafos: a indexação termina assim por abraçar diferentes operações e dar origem a um guia para o texto. Esta última competência, que para nós pode parecer estranha ao cumprimento do compilador de índices, é entendida considerando que no século XVI a publicação das principais edições de antiguidades clássicas ainda estava em andamento.

Neste sentido, Gesner efetivamente foi um indexador ao seu tempo. A sua posição enquanto editor de obras e/ou como leitor, ou seja, tanto daquele que constrói quanto daquele que utiliza os índices, Ihe permitiu formular uma visão multidimensional acerca do processo de indicialização e, subliminarmente, dos processos de mediação da informação e organização do conhecimento no Séc. $\mathrm{XVI}$.

\section{REFERÊNCIAS}

ARAUJO, Andre Vieira de Freitas. Sobre a eminência e o eco da Bibliografia: nos rastros do método bibliográfico gesneriano e dos fundamentos do campo. 2018. $168 \mathrm{f}$. Tese (Doutorado em Ciência da Informação) - Universidade de São Paulo, Escola de Comunicações e Artes, São Paulo, 2018. 
.; CRIPPA, Giulia. Confusa e irritante multidão de livros: relações entre

o contexto histórico-informacional da Europa Moderna e a estrutura

documentária de Bibliotheca Universalis, de Conrad Gesner. InCID: Revista de Ciência da Informação e Documentação, v. 7, p. 224-241, 2016. Disponível em: <http://www.revistas.usp.br/incid/article/view/118774>. Acesso em: 20 fev. 2018.

.; CRIPPA, Giulia; SABBA, Fiammentta. Semantic order in the 16th century: an introductory discussion of Conrad Gesner's Pandectae. In: GUIMARAES, J. A. C. G.; MILANI, S. O.; DODEBEI, V. (Ed.). Knowledge organization for a sustainable world: challenges and perspectives for cultural, scientific, and technological sharing in a connected society. Würzburg: Ergon Verlag, 2016. p. 27-29. Proceedings of the Fourteenth International ISKO Conference, set. 2016, Rio de Janeiro.

BLAIR, Ann. Too much to know: managing scholarly Information before the modern age. Nem Heaven \& London: Yale University Press, 2010.

BURKE, Peter. Problemas causados por Gutenberg: a explosão da informação nos primórdios da Europa moderna. Estudos Avançados, v. 16, n. 44, p. 173185, jan./abr. 2002.

COCHETTI, Maria. Teoria e instruzione degli indici secondo Conrad Gessner. II Bibliotecario: Rivista di Biblioteconomia, Bibliografia e Scienze dell'Informazione, v. 1, p. 25-32, set. 1984a.

Teoria e instruzione degli indici secondo Conrad Gessner (Seguito). II Bibliotecario: Rivista di Biblioteconomia, Bibliografia e Scienze dell'Informazione, v. 2, p. 73-77, dic. 1984b.

CONSIDINE, John. Cutting and pasting slips: early modern compilation and information management. Journal of Medieval and Early Modern Studies, v. 45, n. 3, p. 487-504, set. 2015.

FARIA, Maria Isabel; PERICÃO, Maria da Graça. Dicionário do livro: da escrita ao livro eletrônico. São Paulo: EDUSP, 2008.

GESNER, Conrad. Bibliotheca universalis, sive, Catalogus omnium scriptorum locupletissimus in tribus linguis Latina, Graeca \& Hebraica: extantium \& non extantium, veterum \& recentiorum in hunc usque diem, doctorum \& indoctorum, publicatorum \& in bibliothecis latentium: opus novum \& non Bibliothecis tantum publicis privatisue instituendis necessarium, sed studiosis omnibus cuiuscunque artis aut scientiae ad studia melius formanda utilissimum. Tiguri: apud Christophorum Froschouerum, sep., 1545. Zentralbibliothek Zürich, DrM 3. Public Domain Mark. Disponível em: <http://www.e-rara.ch/doi/10.3931/e-rara-16206>. Acesso em: 05 maio 2018. 
De indicibus librorum. In:

Liber I De Grammatica. In: Titulus XIII De varijs. In: universalium Conradi Gesneri Tigurini, medici \& philosophiae professoris, libri XXI: ad lectores. Secundus hic Bibliothecae nostrae tomus est, totius philosophiae \& omnium bonarum artium atque studiorum locos communes \& ordines universales simul \& particulares complectens [...]. Tiguri: excudebat Christophorus Froschouerus, 1548a. f. [19v (d)] - f. [22v (d4)]. Zentralbibliothek Zürich, 5.13, 2. Public Domain Mark. Disponível em: <https://www.erara.ch/zuz/content/pageview/625009>. Acesso em: 05 maio 2018.

\section{Pandectarum sive partitionum universalium Conradi Gesneri}

Tigurini, medici \& philosophiae professoris, libri XXI: ad lectores. Secundus hic Bibliothecae nostrae tomus est, totius philosophiae \& omnium bonarum artium atque studiorum locos communes \& ordines universales simul \& particulares complectens [...]. Tiguri: excudebat Christophorus Froschouerus, 1548b. Zentralbibliothek Zürich, 5.13, 2. Public Domain Mark. Disponível em: <http://www.e-rara.ch/doi/10.3931/e-rara-1936>. Acesso em: 05 maio 2018.

Partitiones theologicae: pandectarum universalium Conradi Gesneri liber ultimus : Ad lectorem. Pandectis nostris sive secundo Bibliothecae tomo, cuius libri XIX nuper editi sunt, [...]. Tiguri: Christophorus Froschouerus excudit, 1549. Zentralbibliothek Zürich, 5.13, 3. Public Domain Mark. Disponível em: <http://www.e-rara.ch/zuz/content/titleinfo/625727>. Acesso em: 05 maio 2018.

SERRAI, Alfredo. Conrad Gesner. Roma: Bulzoni Editore, 1990.

I loci communes. In: La biblioteca tra informazione e cultura. Pistoia: Settegiorni, 2016. p. 26-53.

Natura elementi e origine della bibliografia in quanto mappa del sapere e dele lettere. Roma: Bulzoni Editore, 2010.

. I Pandectae di Conrad Gesner. Bibliotheca, 1, p. 11-37, 2007.

WELLISCH, Hans. How to make an index - 16th century style: Conrad Gesner on index and catalogs. International Classification, Frankfurt, v. 8, n. 1, p. 1015, 1981. 


\title{
DE INDICIBUS LIBRORUM AND THE ART OF INDICIALIZATION IN CONRAD GESNER: CONTEXT AND PRINCIPLES (PART I)
}

\begin{abstract}
Introduction: This is the first part of the study on De indicibus librorum - an integral part of Conrad Gesner(1516-1565)'s Pandectae (1548) - which deals with the constitution, function and use of indices. Objective: To identify the context and principles that guide De indicibus librorum. Methodology: Under a historical-bibliographic approach, the study has as its course: 1) brief historical-informational and documentary contextualization of De indicibus librorum; 2) mapping, reading and full translation of the Latin text (for Part I of the study, specifically the translation of folio $19 \mathrm{v}$ (d) to folio $21 \mathrm{r}$ (d3); 3) discussion and combination of the Latin source with literature review on the subject, especially from Wellisch (1981), Cochetti (1984a, 1984b) and Serrai (1990). Results: Based on the established cut and the range of folios analyzed, the Gesnerian text presents the motivations, procedures and techniques for composing indexes of books by means of paper strips and, as stated by Gesner, in a "short time" and in the "best order". Gesner recalls indexes of philosophers, theologians, grammarians, philologists and writers, as well as indices of typographers and booksellers. It also shows the indexes as an instrument of patrimonial and bibliographic planning and control. For the Swiss polymath, the indexes are of great use to scholars, as they help to remember things read or present new things, in addition to saving the reader's time. Conclusions: Conrad Gesner, presenting a technical and cultural landscape on the constitution, function and use of indices, criticizes the indicialization of indexes, such as the construction of indexes without the previous reading of the text, which today would represent an opposite perspective of the one postulated by the documentary reading for indexation purposes. At the same time, Gesner stresses the importance of semantic indexes, a question that is also relevant to the field of contemporary indexing. In this sense, Gesner was effectively an "indexer" of his time. His position, whether as a publisher of works and / or as a reader, that is, both the one who constructs and the one who uses the indexes, allowed him to formulate a multidimensional vision about the process of indicialization and, subliminally, the processes of information mediation and knowledge organization in the 16th century.
\end{abstract}

Descriptors: De indicibus librorum [f. 19v (d) -21r (d3)]. Indicialization. Index - History and Theory. Indexing - History and Theory. Pandectae (1548, 1549). Organization of Knowledge - 16th Century.

\section{DE INDICIBUS LIBRORUM Y EL ARTE DE INDICIALIZACIÓN EN CONRAD GESNER: CONTEXTO Y PRINCÍPIOS (PARTE I)}

\begin{abstract}
RESUMEN
Introducción: Se trata de la primeira parte del estúdio sobre De indicibus librorum sección integrante de las Pandectae (1548) de Conrad Gesner (1516-1565) - que trata de la constitución, función y uso de índices. Objetivo: Identificar el contexto y principios que guían De indicibus librorum. Metodología: Bajo enfoque histórico-bibliográfico, el
\end{abstract}


estudio tiene como recorrido: 1) breve contextualización histórico-informacional y documental de De indicibus librorum; 2) mapeamiento, lectura y traducción integral del texto latino (para la Parte I del estudio, específicamente la traducción del folio 19v (d) al folio $21 \mathrm{r}(\mathrm{d} 3)$ ); 3) discusión y combinación de la fuente latina con la revisión de literatura sobre el tema, sobre todo a partir de Wellisch (1981), Cochetti (1984a, 1984b) y Serrai (1990). Resultados: A partir del recorte establecido, el texto gesneriano presenta las motivaciones, procedimientos y técnicas para la composición de índices de libros y expone estrategias para la elaboración de índices en poco tiempo y en el mejor orden. Gesner rememora índices de filósofos, teólogos, gramáticos, filólogos y escritores. También menciona índices de tipógrafos y libreros. Conclusiones: Conrad Gesner, al presentar un paisaje técnico y cultural sobre la constitución, función y uso de los índices, tece críticas fundamentales en relación a la indicialización, a ejemplo de la construcción de índices sin la lectura previa del texto, lo que hoy representaría una perspectiva opuesta de aquella postulada por la lectura documental para fines de indexación. Al mismo tiempo, Gesner destaca la importancia de los índices semánticos, cuestión también relevante al campo de la indexación contemporánea. En este sentido, Gesner efectivamente fue un "indizador" a su tiempo. Su posición, ya sea como editor de obras y / o como lector, es decir, tanto de aquel que construye como de aquel que utiliza los índices, le permitió formular una visión multidimensional acerca del proceso de indicialización y, subliminal, de los procesos de mediación de la información y organización del conocimiento en el siglo XVI.

Descriptores: De indicibus librorum [f. 19v (d) - 21r (d3)]. Indicializacion. Índice - Historia y Teoría. Indización - Historia y Teoría. Pandectae (1548, 1549). Organización del Conocimiento - Siglo XVI.

Recebido: 10.05 .2018

Aceito: 25.08.2018

Inf. Inf., Londrina, v. 23, n. 2, p. 14 - 37, maio/ago. 2018.

http://www.uel.br/revistas/informacao/ 